\title{
How Robust are Journal Rankings Based on the Impact Factor? Evidence from the Economic Sciences
}

\author{
Christian Seiler \\ Klaus Wohlrabe
}

\author{
CESIFO WORKING PAPER NO. 5036 \\ CATEGORY 12: EMPIRICAL AND THEORETICAL METHODS \\ OCTOBER 2014
}
An electronic version of the paper may be downloaded
- from the SSRN website: Www.SSRN.com
- from the RePEc website: Www.RePEc.org
- from the CESifo website: www.CESifo-group.org/wp

\section{CESifo}




\title{
How Robust are Journal Rankings Based on the Impact Factor? Evidence from the Economic Sciences
}

\begin{abstract}
It is well-known that the distribution of citations to articles in a journal is skewed. We ask whether journal rankings based on the impact factor are robust with respect to this fact. We exclude the most cited paper, the top 5 and 10 cited papers for 100 economics journals and recalculate the impact factor. Afterwards we compare the resulting rankings with the original ones from 2012. Our results show that the rankings are relatively robust. This holds both for the 2-year and the 5-year impact factor.
\end{abstract}

JEL-Code: A120, A140.

Keywords: impact factor, ranking, skewness, economics journals.

\author{
Christian Seiler* \\ Ifo Institute - Leibniz Institute for \\ Economic Research \\ at the University of Munich \\ Poschingerstrasse 5 \\ Germany-81679 Munich \\ seiler@ifo.de
}

\author{
Klaus Wohlrabe \\ Ifo Institute - Leibniz Institute for \\ Economic Research \\ at the University of Munich \\ Poschingerstrasse 5 \\ Germany-81679 Munich \\ wohlrabe@ifo.de
}




\section{Introduction}

Journals rankings have gained more interest, visibility and importance recently. Scientists with publications in high-ranked journals have a higher probability of getting tenure, research funding or reputation. The number of journal rankings has increased in recent years, which might be both due to better data availability, the increased competition amongst the science community and the need for a permanent research evaluation. Finally, people seem to be fascinated by rankings. Still the most visible ranking is the one based on the 2-year impact factor from the Journal Citation Reports. For many journals publishers state the impact factor (IF) on the corresponding website. Furthermore, they note that it is ranked on position $X$ in category $Y$. Although often criticized in bibliometric literature the impact factor is still one of the cornerstones for the evaluation of journals 1

In this short article we investigate the robustness of journal rankings based on the impact factor. We do this by acknowledging the well-known fact that the distribution of citations to articles in a journal is skewed (Folly, Hajtman, Nagy, and Ruff (1981), Seglen (1992) or Wall $(2009))$. Does the relative ranking change if we exclude the top paper or the best $x$ papers in terms of citations? Suppose a specific article generates $90 \%$ of all citations relevant for the impact factor of the journal. Is then the quality of the journal overstated or misplaced in the journal ranking? We investigate this issue for 100 economics journals using the IF and the corresponding citations from 2012. We show that the rankings based on the impact factor only change marginally if we exclude the top, the top 5 or the top 10 cited papers for each journal, i.e. the ranking is robust with respect to the skewness of the citation distribution. There are some larger (downward) movements for certain journals which gather most of its citations on only few articles. As a consequence many journals show small ranking improvements.

Our paper is closely related to the literature concerning the uncertainty of impact factors. Vanclay (2012), Leydesdorff and Opthof (2010), and Moed, Colledge, Reedijk, Moya-Anegon, Guerrero-Bote, Plume, and Amin (2012) called for confidence intervals to be provided for the impact factors. Such uncertainty measures can be found in Schubert and Glänzel (1983),

\footnotetext{
${ }^{1}$ See Archambault and Larivière (2009) or Vanclay 2012) for details and further references.
} 
Nieuwenhuysen and Rousseau (1988), Opthof (1997), Chen, Jen, and Wu (2014), Greenwood (2007), and Stern (2013). The latter two articles show that, besides the very top journals, a distinct discrimination in terms of the level of the impact factor between closely spaced journals is not possible. It also adds to the discussion whether authors can "free-ride" on power laws (Baum 2011), i.e. profit from few articles which push the impact factor. Our results suggest that potential free-riding is even more pronounced for lower ranked journals.

\section{Data}

From Web of Science we collected all citations in 2012 to each article published in the years 2007 to 2011 in the Journal Citation Report economics subject category by Thomson Reuters. We focus on the top 100 journals in economics according to the impact factor in 2012. Based on our data set, we recalculated the 2-year and 5-year impact factors for all journals in our sample. We observed some minor differences to the official impact factors released in the Journal Citation Report which were caused by a different number of citations or articles. These differences were also found and discussed in other studies, e.g. Leydesdorff and Opthof (2010), Opthof (1997) and Stern (2013). In Figure 1 (a) we plot the empirical skewness coefficient against the 2-year IF. All citation distributions have positive skewness coefficients, i.e. they are skewed to the left. Furthermore, we see that the higher the 2-year IF the less skewed are the citations distributions.

In addition to the skewness we take a look at some other measures indicating skewness in the citation distribution: the share of non-cited papers, the Gini coefficient, the normalized Herfindhal-Hirschmann index and the coefficient of variation. The share of non-cited papers is defined as the number of papers which made no contribution to the impact factor in terms of citations. The Gini coefficient describes how equal the citations are distributed. If the Gini coefficient is zero, the citations are equally distributed across papers. In case that it is close to one all citations are concentrated on a single paper. The normalized HerfindhalHirschmann index is also a concentration measure which ranges from 0 (equal distribution) to 1 (completely unequal distribution). In contrast to the Gini coefficient it utilizes the squared 
values of the single subjects. The coefficient of variation is the ratio of the standard deviation of the citations and its average. As the variance is usually higher for journals with higher average citation count, the coefficient of variation is the more appropriate solution in our case as it normalizes the variance by the mean.

In Figure 1 (b) to (e) we plot all four indicators in relation to the respective impact factor $2^{2}$ The results are clear cut: The higher the impact factor the lesser the values of skewness indicators. For a journal with a higher impact factor the citations are usually less unequally distributed, the share of non-cited papers and the coefficient of variation are lower ${ }^{3}$

\section{$3 \quad$ Results}

In Table 3 we rank the 100 economics journals with respect to the 2-year IF from 2012. In a second step we exclude the top cited paper for each journal, recalculate the impact factor and rank them again. We do the same by excluding the top 5 and the top 10 papers in terms of citation counts. In case that the relative position remained unchanged compared to the original 2-year IF ranking we labeled this with a $\bigcirc$. An improvement or decline is marked with a $\Delta$ and $\boldsymbol{\nabla}$, respectively. Furthermore, we report in brackets the share of citations represented by the top 1, 5 and 10 papers. In order to get an overall impression we plot in Figure 2 the ranking based on the standard 2-year IF against our new calculated rankings. Circles on the 45 degree the line denote that the relative rank remained unchanged. Journals above or below line lost or gained ranking positions. Looking at the new ranking without the top-cited paper one can see that the ranking remains strongly robust. The Spearman rank-correlation is extremely high (0.994) and only minor ranking shifts were found. This is confirmed if we look at the largest gains and losses reported in Table 1. The largest drops are 16 positions for the two journals Economy $\&$ Society and Economic Systems Research which have also large shares of the top-cited paper (25\%). These losses are compensated by rather small ranking improvements. The Journal of Economic Literature, which publishes only reviews and survey

\footnotetext{
${ }^{2}$ The corresponding values are reported in the appendix in Table 4.

${ }^{3}$ The results remain qualitatively the same for the 5 -year IF.
} 
Figure 1: Citation distribution indicators against the 2-year impact factor

(a)

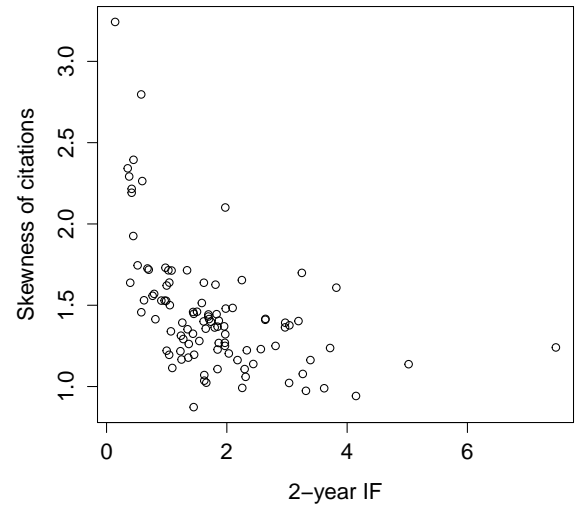

(c)

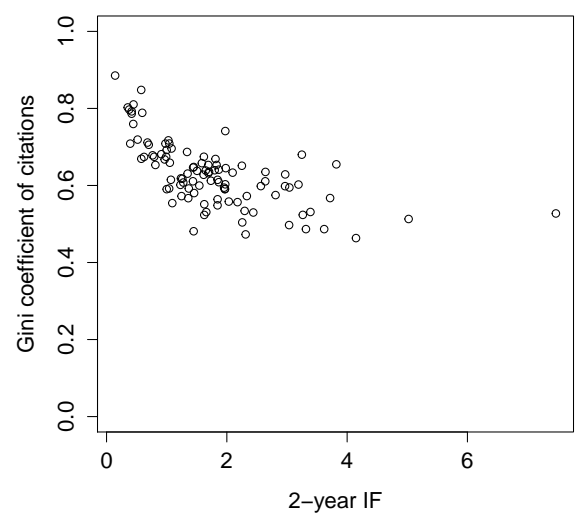

(b)

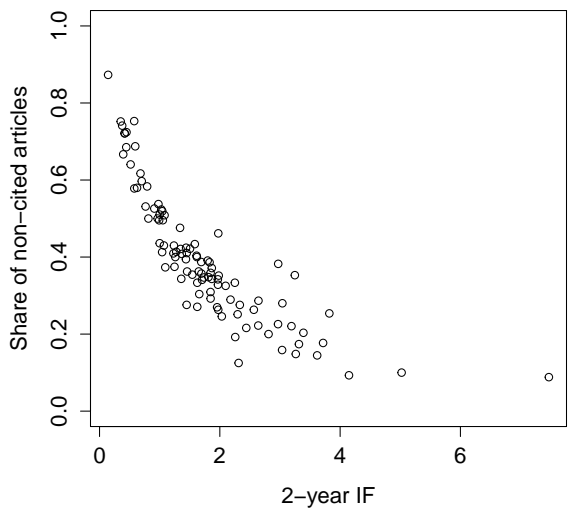

(d)

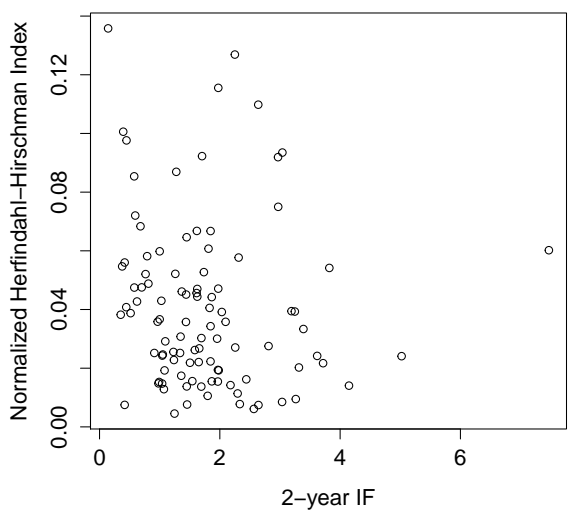

(e)

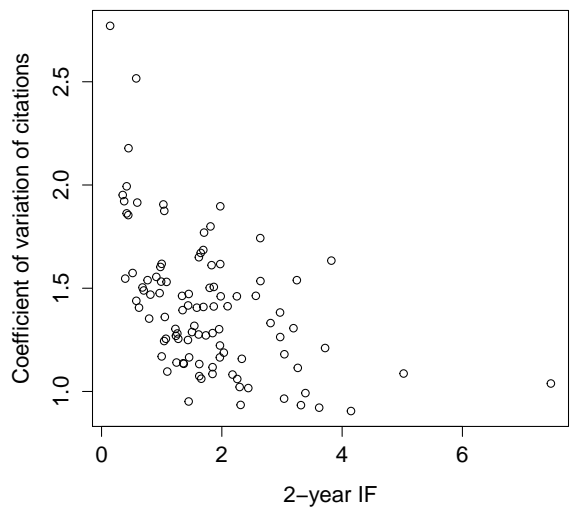


articles, stays at the top compared to the original ranking. The other top 10 journals remain the same with one exception: the journal Technological $\&$ Economic Development of Economy leaves the top 10 and is replaced by the Review of Financial Studies. If we drop the top 5 and 10 papers than Figure 2 seems to suggest that the rankings are not that robust as in first place, when we drop only the top-cited paper. Taking a closer look shows there are some journals with large drops (see Table 1) which leads to automatic (small) position gains for many journals. The rank correlations with 0.944 and 0.862 are still very high. The Review of Financial Studies also enters in both cases the top 10 journals after excluding the top cited papers.

We repeat the whole analysis for the 5-year IF. The individual ranks for each journal are given in the right panel of Table 3, the summarizing graphs are shown in the lower panel of Figure 2. The rank correlations are with 0.997, 0.978 and 0.936 even higher, i.e. the rankings are more robust compared to the 2-year IF. This also confirmed by Table 2 where the largest relative ranking movements are smaller compared to Table 1. The Quarterly Journal of Economics is the top journal in all four rankings.

\section{Conclusion}

This paper investigates the robustness of journal rankings incorporating the well-documented skewness in citation distribution of articles. Using the best 100 economics journals from 2012 we show that the relative ranking remains relatively stable after excluding the best, the top 5 and top 10 papers. The results hold both for the 2-year and the 5-year IF. For the latter one they are even more robust. Therefore, the skewness of citations has no major impact on journal rankings based on the impact factor. Future research should investigate whether our results also hold in other scientific areas. 
Table 1: Relative citation shares and ranking shifts for the 2-year IF

\begin{tabular}{|c|c|c|c|}
\hline Smallest and largest relative sha & & Maximum and minimum ranking shi & \\
\hline \multicolumn{4}{|c|}{ w/o Top 1} \\
\hline Journal of Banking \& Finance & $1 \%$ & Value in Health & 6 \\
\hline Energy Economics & $2 \%$ & Economic Journal & 6 \\
\hline World Development & $2 \%$ & Journal of Environ. Econ. \& Manage. & 5 \\
\hline Review of Financial Studies & $2 \%$ & Journal of Monetary Economics & 5 \\
\hline Review of Economics \& Statistics & $3 \%$ & Economics \& Human Biology & 4 \\
\hline Journal of Economic Growth & $22 \%$ & Economy \& Society & -16 \\
\hline Japanese Economic Review & $22 \%$ & Economic Systems Research & -16 \\
\hline Economic Systems Research & $25 \%$ & Economic Geography & -7 \\
\hline Economy \& Society & $25 \%$ & Energy Journal & -6 \\
\hline Economic Geography & $28 \%$ & Journal of Economic Growth & -6 \\
\hline \multicolumn{4}{|c|}{ w/o Top 5} \\
\hline Journal of Banking \& Finance & $6 \%$ & Journal of Banking \& Finance & 18 \\
\hline Applied Economics & $9 \%$ & World Development & 18 \\
\hline Energy Economics & $9 \%$ & Value in Health & 16 \\
\hline World Development & $9 \%$ & Journal of Health Economics & 15 \\
\hline Review of Financial Studies & $10 \%$ & Journal of Environ. Econ. \& Manage. & 12 \\
\hline Japan \& the World Economy & $58 \%$ & Economic Systems Research & -46 \\
\hline Brookings Papers on Econ. Activity & $61 \%$ & Journal of Economic Growth & -44 \\
\hline Japanese Economic Review & $67 \%$ & Economy \& Society & -20 \\
\hline Economic Systems Research & $68 \%$ & Brookings Papers on Econ. Activity & -18 \\
\hline Journal of Economic Growth & $69 \%$ & Economic Geography & -16 \\
\hline \multicolumn{4}{|c|}{ w/o Top 10} \\
\hline Journal of Banking \& Finance & $10 \%$ & Journal of Banking \& Finance & 32 \\
\hline Applied Economics & $15 \%$ & World Development & 28 \\
\hline World Development & $16 \%$ & Journal of Health Economics & 25 \\
\hline Energy Economics & $17 \%$ & Journal of Public Economics & 20 \\
\hline Review of Financial Studies & $17 \%$ & Value in Health & 20 \\
\hline Economic Systems Research & $82 \%$ & Brookings Papers on Econ. Activity & -58 \\
\hline Brookings Papers on Econ. Activity & $86 \%$ & Journal of Economic Growth & -56 \\
\hline Journal of Economic Growth & $89 \%$ & Economic Systems Research & -49 \\
\hline Developing Economies & $92 \%$ & IMF Economic Review & -36 \\
\hline Japanese Economic Review & $100 \%$ & Rev. of Environ. Economics \& Policy & -30 \\
\hline
\end{tabular}


Table 2: Relative citation shares and ranking shifts for the 5-year IF

\begin{tabular}{|c|c|c|c|}
\hline \multicolumn{2}{|l|}{ Smallest and largest relative shares } & \multicolumn{2}{|l|}{ Maximum and minimum ranking shifts } \\
\hline \multicolumn{4}{|c|}{ w/o Top 1} \\
\hline Journal of Banking \& Finance & $1 \%$ & Environmental \& Resource Economics & 5 \\
\hline Applied Economics & $1 \%$ & Ecological Economics & 3 \\
\hline Journal of Finance & $1 \%$ & International Journal of Forecasting & 3 \\
\hline Ecological Economics & $2 \%$ & Journal of Public Economics & 3 \\
\hline Journal of Public Economics & $2 \%$ & Review of Economics \& Statistics & 3 \\
\hline Socio-Economic Review & $13 \%$ & Brookings Papers on Econ. Activity & -4 \\
\hline Open Economies Review & $14 \%$ & International Environ. Agreements & -4 \\
\hline Brookings Papers on Econ. Activity & $14 \%$ & Socio-Economic Review & -4 \\
\hline IMF Economic Review & $16 \%$ & IMF Economic Review & -7 \\
\hline Journal of Economic Literature & $17 \%$ & Applied Econ. Perspectives \& Policy & -7 \\
\hline \multicolumn{4}{|c|}{ w/o Top 5} \\
\hline Journal of Banking \& Finance & $4 \%$ & Journal of Banking \& Finance & 13 \\
\hline Applied Economics & $4 \%$ & International Journal of Forecasting & 12 \\
\hline Energy Economics & $5 \%$ & Environ. \& Resource Economics & 10 \\
\hline World Development & $6 \%$ & Journal of Economic Psychology & 9 \\
\hline Ecological Economics & $6 \%$ & Journal of Agricultural Economics & 9 \\
\hline Brookings Papers on Econ. Activity & $38 \%$ & Applied Econ. Perspectives \& Policy & -13 \\
\hline Journal of Economic Growth & $40 \%$ & Brookings Papers on Econ. Activity & -13 \\
\hline Journal of Economic Literature & $44 \%$ & International Environ. Agreements & -13 \\
\hline Economic Systems Research & $45 \%$ & IMF Economic Review & -17 \\
\hline IMF Economic Review & $48 \%$ & Economic Systems Research & -26 \\
\hline \multicolumn{4}{|c|}{ w/o Top 10} \\
\hline Journal of Banking \& Finance & $6 \%$ & International Journal of Forecasting & 19 \\
\hline Applied Economics & $7 \%$ & Journal of Banking \& Finance & 18 \\
\hline Energy Economics & $9 \%$ & Journal of Economic Theory & 16 \\
\hline Ecological Economics & $10 \%$ & Journal of Economic Psychology & 14 \\
\hline World Development & $10 \%$ & Journal of Agricultural Economics & 12 \\
\hline Applied Econ. Perspectives \& Policy & $55 \%$ & Brookings Papers on Econ. Activity & -20 \\
\hline Economic Systems Research & $61 \%$ & Socio-Economic Review & -21 \\
\hline Journal of Economic Growth & $62 \%$ & Journal of Economic Growth & -25 \\
\hline Journal of Economic Literature & $68 \%$ & Economic Systems Research & -28 \\
\hline IMF Economic Review & $78 \%$ & IMF Economic Review & -54 \\
\hline
\end{tabular}

See Table 1 for explanations. All results refer to the 5-year IF. 
Figure 2: Ranking comparisons for the 2-year and 5-year IF
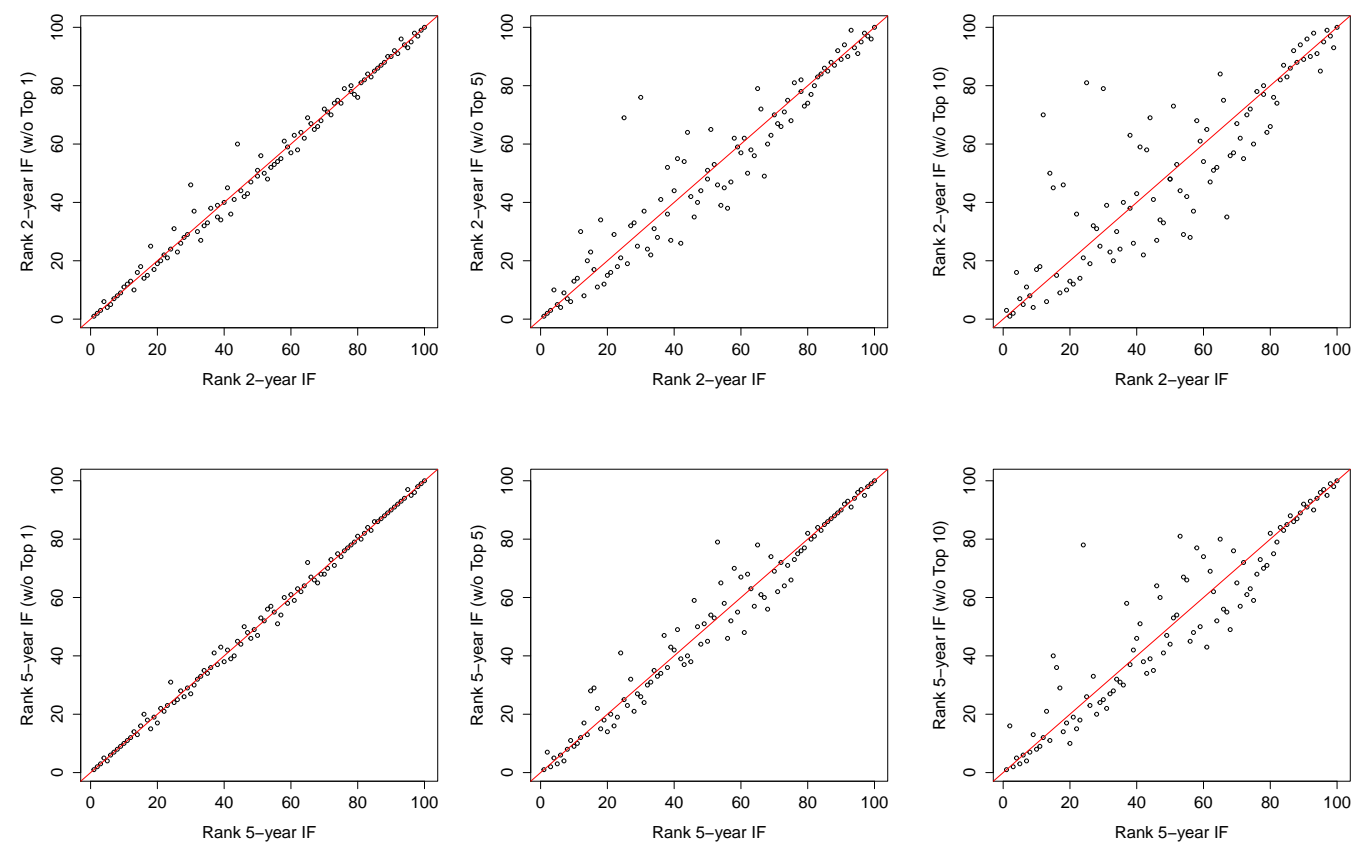


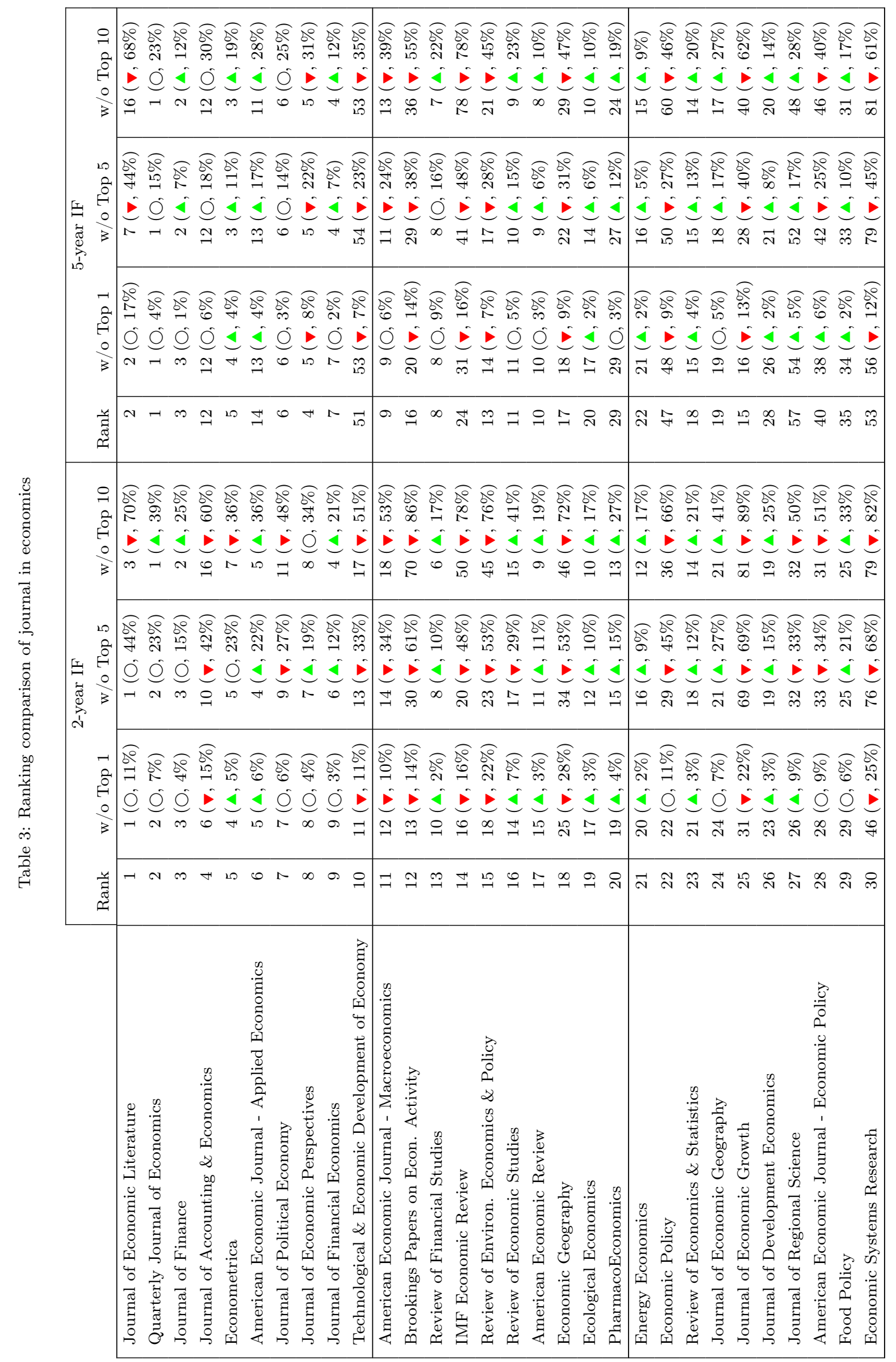




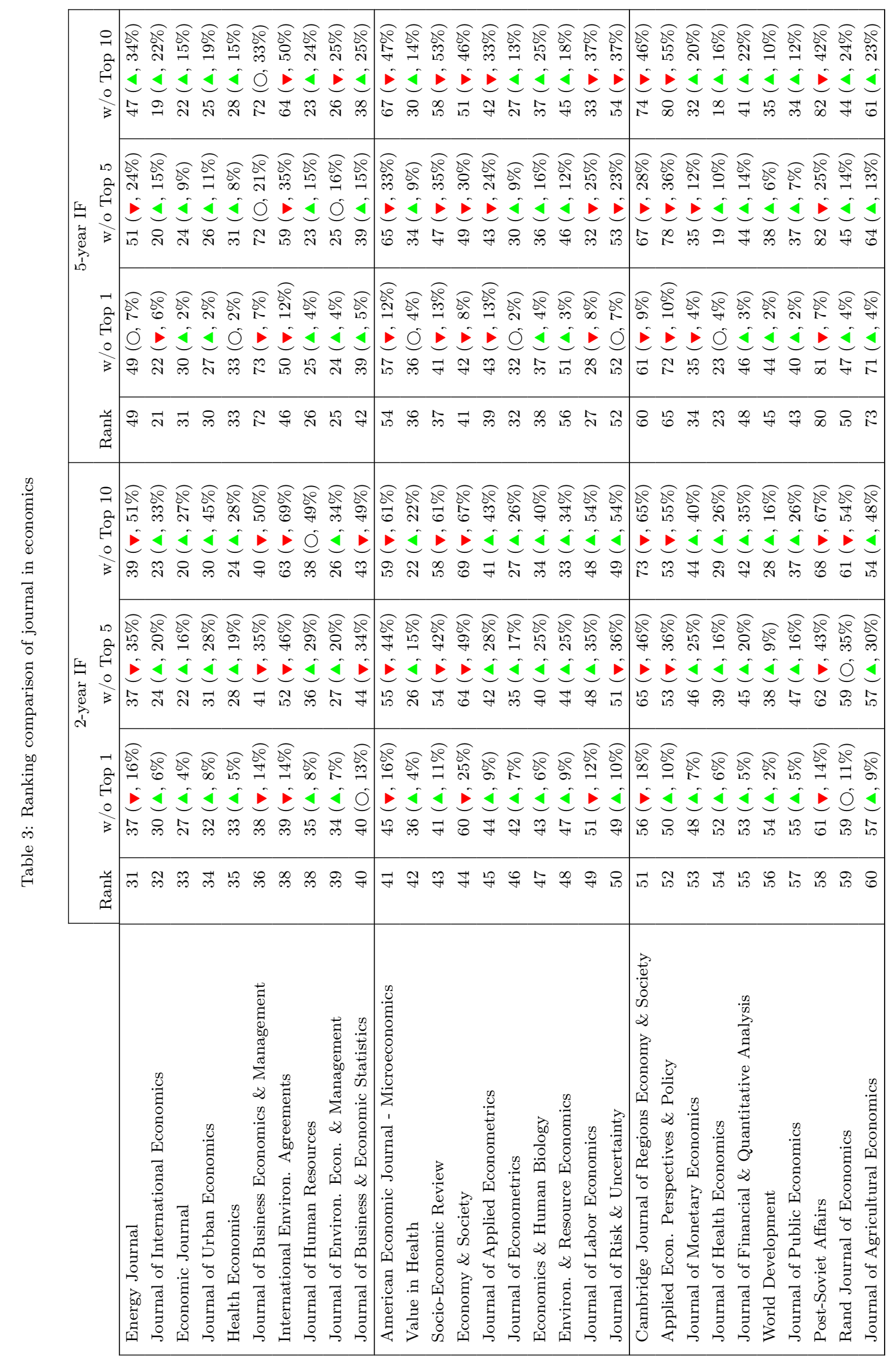




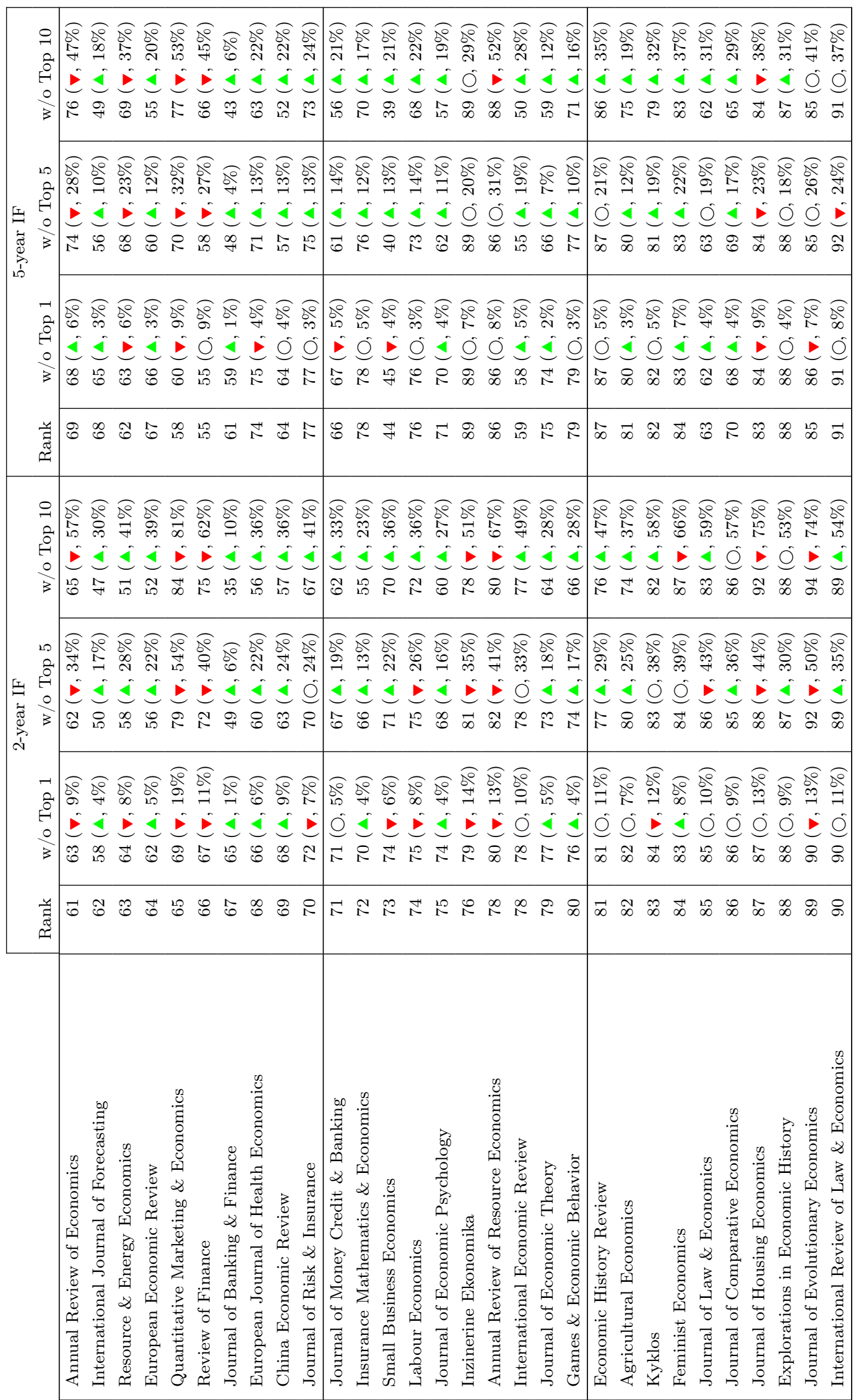




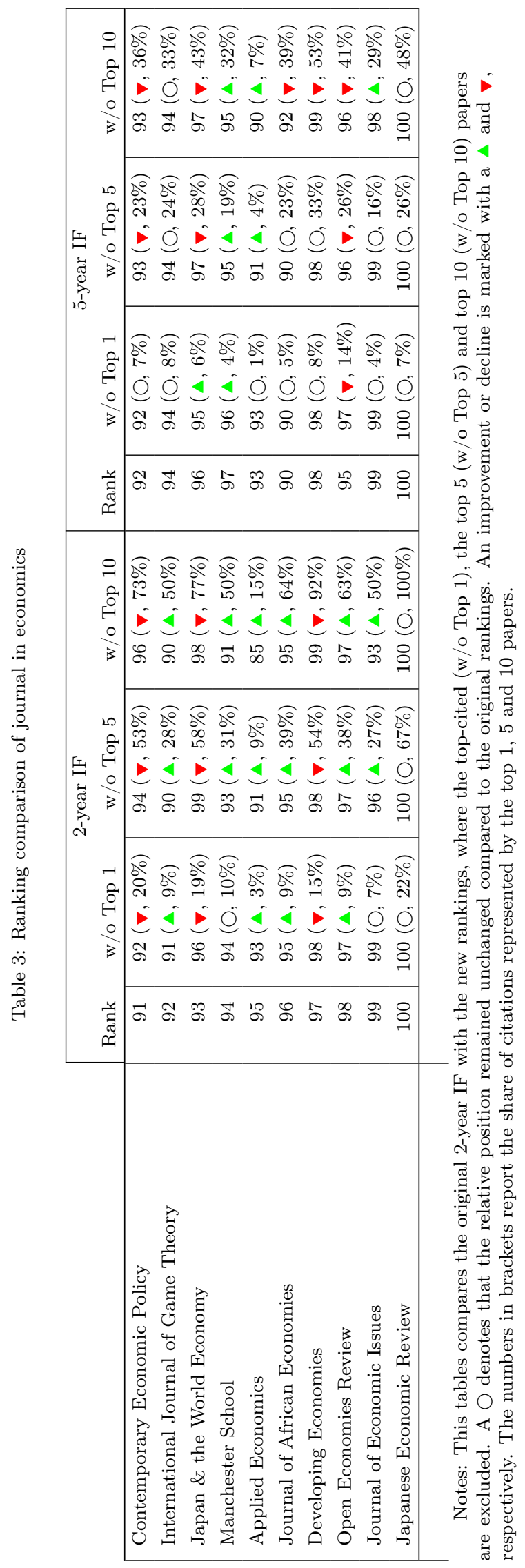




\section{References}

Archambault, É., and V. Larivière (2009): "History of the journal impact factor: Contingencies and consequences," Scientometrics, 79(3), 635-649.

BAum, J. A. (2011): "Free-riding on power laws: Questioning the validity of the impact factor as a measure of research quality in organization studies," Organization, 18(4), 449-466.

Chen, K.-M., T.-H. Jen, And M. Wu (2014): "Estimating the accuracies of journal impact factor through bootstrap," Journal of Informetrics, 8(1), 181-196.

Folly, G., B. Hajtman, J. Nagy, and I. Ruff (1981): "Some methodological problems in ranking scientists by citation analysis," Scientometrics, 3(2), 135-147.

Greenwood, D. C. (2007): "Reliability of journal impact factor rankings," BMC Medical Research Methodology, 7(1), 48.

LeydesdorfF, L., And T. Opthof (2010): "Scopus's source normalized impact per paper (SNIP) versus a journal impact factor based on fractional counting of citations," Journal of the American Society for Information Science and Technology, 61(11), 2365-2369.

Moed, H. F., L. Colledge, J. Reediuk, F. Moya-Anegon, V. Guerrero-Bote, A. Plume, and M. Amin (2012): "Citation-based metrics are appropriate tools in journal assessment provided that they are accurate and used in an informed way," Scientometrics, 92(2), 367-376.

Nieuwenhuysen, P., And R. Rousseau (1988): "A quick and easy method to estimate the random effect on citation measures," Scientometrics, 13(1-2), 45-52.

Opthof, T. (1997): "Sense and nonsense about the impact factor," Cardiovascular Research, $33(1), 1-7$.

Schubert, A., And W. GlÄnzel (1983): "Statistical reliability of comparisons based on the citation impact of scientific publications," Scientometrics, 5(1), 59-73. 
Seglen, P. O. (1992): "The skewness of science," Journal of the American Society for Information Science, 43(9), 628-638.

Stern, D. I. (2013): "Uncertainty Measures for Economics Journal Impact Factors," Journal of Economic Literature, 51(1), 173-189.

VANCLAY, J. K. (2012): "Impact factor: outdated artefact or stepping-stone to journal certification?," Scientometrics, 92(2), 211-238.

Wall, H. (2009): "Don't Get Skewed over by Journal Rankings," The BE Journal of Economic Analysis $\&$ Policy, 9(1), 34.

\section{Appendix}

Table 4: Skewness indices

\begin{tabular}{|c|c|c|c|c|c|}
\hline Journal & Skewness & $\mathrm{NC}$ & Gini & HHI & $\mathrm{VC}$ \\
\hline Agricultural Economics & 1.529 & 0.526 & 0.681 & 0.025 & 1.555 \\
\hline American Economic Journal - Applied Economics & 0.989 & 0.145 & 0.487 & 0.024 & 0.922 \\
\hline American Economic Journal - Economic Policy & 1.203 & 0.246 & 0.558 & 0.039 & 1.188 \\
\hline American Economic Journal - Macroeconomics & 1.403 & 0.221 & 0.602 & 0.039 & 1.306 \\
\hline American Economic Journal - Microeconomics & 1.627 & 0.348 & 0.669 & 0.061 & 1.799 \\
\hline American Economic Review & 1.416 & 0.287 & 0.635 & 0.007 & 1.535 \\
\hline Annual Review of Economics & 1.262 & 0.408 & 0.592 & 0.046 & 1.134 \\
\hline Annual Review of Resource Economics & 1.621 & 0.510 & 0.692 & 0.037 & 1.618 \\
\hline Applied Econ. Perspectives \& Policy & 1.400 & 0.404 & 0.628 & 0.046 & 1.276 \\
\hline Applied Economics & 2.192 & 0.721 & 0.792 & 0.007 & 1.994 \\
\hline Brookings Papers on Econ. Activity & 1.377 & 0.280 & 0.595 & 0.093 & 1.180 \\
\hline Cambridge Journal of Regions Economy \& Society & 1.638 & 0.400 & 0.675 & 0.067 & 1.650 \\
\hline China Economic Review & 1.217 & 0.410 & 0.602 & 0.026 & 1.303 \\
\hline Contemporary Economic Policy & 2.797 & 0.753 & 0.848 & 0.085 & 2.516 \\
\hline Developing Economies & 1.638 & 0.667 & 0.709 & 0.101 & 1.547 \\
\hline Ecological Economics & 1.230 & 0.263 & 0.598 & 0.006 & 1.463 \\
\hline Econometrica & 1.237 & 0.177 & 0.567 & 0.022 & 1.210 \\
\hline Economic Geography & 1.411 & 0.222 & 0.611 & 0.110 & 1.743 \\
\hline Economic History Review & 1.528 & 0.500 & 0.668 & 0.036 & 1.476 \\
\hline Economic Journal & 1.269 & 0.342 & 0.590 & 0.015 & 1.165 \\
\hline Economic Policy & 1.060 & 0.125 & 0.473 & 0.058 & 0.935 \\
\hline Economic Systems Research & 2.101 & 0.462 & 0.741 & 0.116 & 1.897 \\
\hline Economics \& Human Biology & 1.024 & 0.304 & 0.531 & 0.027 & 1.062 \\
\hline Economy \& Society & 1.415 & 0.341 & 0.635 & 0.092 & 1.769 \\
\hline Energy Economics & 1.223 & 0.276 & 0.573 & 0.008 & 1.158 \\
\hline
\end{tabular}

Continued on next page. 
Table 4 - cont. from previous page.

\begin{tabular}{|c|c|c|c|c|c|}
\hline Journal & Skewness & $\mathrm{NC}$ & Gini & HHI & $\mathrm{VC}$ \\
\hline Energy Journal & 1.322 & 0.263 & 0.603 & 0.047 & 1.617 \\
\hline Environ. \& Resource Economics & 1.356 & 0.363 & 0.639 & 0.022 & 1.671 \\
\hline European Economic Review & 1.715 & 0.476 & 0.687 & 0.025 & 1.463 \\
\hline European Journal of Health Economics & 1.313 & 0.430 & 0.618 & 0.023 & 1.270 \\
\hline Explorations in Economic History & 1.531 & 0.580 & 0.674 & 0.043 & 1.406 \\
\hline Feminist Economics & 1.570 & 0.583 & 0.674 & 0.058 & 1.353 \\
\hline Food Policy & 1.479 & 0.352 & 0.645 & 0.019 & 1.461 \\
\hline Games \& Economic Behavior & 1.731 & 0.537 & 0.709 & 0.015 & 1.603 \\
\hline Health Economics & 1.405 & 0.371 & 0.641 & 0.016 & 1.506 \\
\hline IMF Economic Review & 1.393 & 0.382 & 0.629 & 0.075 & 1.264 \\
\hline Insurance Mathematics \& Economics & 1.339 & 0.430 & 0.615 & 0.013 & 1.255 \\
\hline International Economic Review & 1.221 & 0.436 & 0.590 & 0.060 & 1.170 \\
\hline International Environ. Agreements & 1.228 & 0.292 & 0.564 & 0.034 & 1.118 \\
\hline International Journal of Forecasting & 1.178 & 0.344 & 0.567 & 0.017 & 1.137 \\
\hline International Journal of Game Theory & 1.745 & 0.640 & 0.719 & 0.039 & 1.574 \\
\hline International Review of Law \& Economics & 1.457 & 0.578 & 0.669 & 0.047 & 1.439 \\
\hline Inzinerine Ekonomika & 1.715 & 0.523 & 0.717 & 0.043 & 1.906 \\
\hline Japan \& the World Economy & 2.395 & 0.724 & 0.810 & 0.098 & 2.178 \\
\hline Japanese Economic Review & 3.243 & 0.873 & 0.885 & 0.136 & 2.771 \\
\hline Journal of Accounting \& Economics & 1.608 & 0.254 & 0.655 & 0.054 & 1.634 \\
\hline Journal of African Economies & 2.216 & 0.722 & 0.786 & 0.056 & 1.863 \\
\hline Journal of Agricultural Economics & 1.325 & 0.394 & 0.611 & 0.036 & 1.249 \\
\hline Journal of Applied Econometrics & 1.443 & 0.357 & 0.632 & 0.030 & 1.409 \\
\hline Journal of Banking \& Finance & 1.166 & 0.375 & 0.572 & 0.005 & 1.140 \\
\hline Journal of Business \& Economic Statistics & 1.445 & 0.386 & 0.653 & 0.041 & 1.612 \\
\hline Journal of Business Economics \& Management & 1.268 & 0.343 & 0.608 & 0.044 & 1.412 \\
\hline Journal of Comparative Economics & 1.719 & 0.597 & 0.706 & 0.048 & 1.489 \\
\hline Journal of Development Economics & 1.163 & 0.289 & 0.557 & 0.014 & 1.082 \\
\hline Journal of Econometrics & 1.431 & 0.387 & 0.653 & 0.014 & 1.685 \\
\hline Journal of Economic Geography & 0.992 & 0.192 & 0.504 & 0.027 & 1.060 \\
\hline Journal of Economic Growth & 1.655 & 0.333 & 0.651 & 0.127 & 1.461 \\
\hline Journal of Economic Issues & 2.342 & 0.752 & 0.803 & 0.038 & 1.952 \\
\hline Journal of Economic Literature & 1.240 & 0.088 & 0.527 & 0.060 & 1.039 \\
\hline Journal of Economic Perspectives & 0.974 & 0.174 & 0.487 & 0.020 & 0.934 \\
\hline Journal of Economic Psychology & 1.195 & 0.413 & 0.592 & 0.015 & 1.244 \\
\hline Journal of Economic Theory & 1.527 & 0.495 & 0.675 & 0.015 & 1.532 \\
\hline Journal of Environ. Econ. \& Management & 1.107 & 0.309 & 0.548 & 0.022 & 1.085 \\
\hline Journal of Evolutionary Economics & 2.264 & 0.687 & 0.789 & 0.072 & 1.915 \\
\hline Journal of Finance & 0.942 & 0.093 & 0.463 & 0.014 & 0.905 \\
\hline Journal of Financial \& Quantitative Analysis & 1.460 & 0.421 & 0.638 & 0.022 & 1.288 \\
\hline Journal of Financial Economics & 1.077 & 0.148 & 0.524 & 0.009 & 1.114 \\
\hline Journal of Health Economics & 1.280 & 0.354 & 0.600 & 0.016 & 1.318 \\
\hline Journal of Housing Economics & 1.726 & 0.617 & 0.711 & 0.068 & 1.504 \\
\hline Journal of Human Resources & 1.368 & 0.359 & 0.615 & 0.067 & 1.283 \\
\hline Journal of International Economics & 1.250 & 0.328 & 0.591 & 0.019 & 1.223 \\
\hline Journal of Labor Economics & 1.071 & 0.333 & 0.551 & 0.047 & 1.133 \\
\hline Journal of Law \& Economics & 1.558 & 0.531 & 0.678 & 0.052 & 1.539 \\
\hline Journal of Monetary Economics & 1.514 & 0.434 & 0.658 & 0.026 & 1.406 \\
\hline
\end{tabular}

Continued on next page. 
Table 4 - cont. from previous page.

\begin{tabular}{|c|c|c|c|c|c|}
\hline Journal & Skewness & $\mathrm{NC}$ & Gini & HHI & $\mathrm{VC}$ \\
\hline Journal of Money Credit \& Banking & 1.714 & 0.509 & 0.696 & 0.019 & 1.531 \\
\hline Journal of Political Economy & 1.163 & 0.203 & 0.531 & 0.033 & 0.992 \\
\hline Journal of Public Economics & 1.447 & 0.410 & 0.648 & 0.014 & 1.472 \\
\hline Journal of Regional Science & 1.483 & 0.325 & 0.633 & 0.036 & 1.413 \\
\hline Journal of Risk \& Insurance & 1.114 & 0.373 & 0.554 & 0.029 & 1.096 \\
\hline Journal of Risk \& Uncertainty & 1.036 & 0.271 & 0.524 & 0.044 & 1.074 \\
\hline Journal of Urban & 1.370 & 0.270 & 0.594 & 0.030 & 1.302 \\
\hline Kyklos & 1.414 & 0.500 & 0.653 & 0.049 & 1.469 \\
\hline Labour Economics & 1.639 & 0.519 & 0.709 & 0.024 & 1.874 \\
\hline Manchester School & 1.926 & 0.685 & 0.760 & 0.041 & 1.854 \\
\hline Open Economies Review & 2.292 & 0.741 & 0.797 & 0.055 & 1.921 \\
\hline PharmacoEconomics & 1.139 & 0.216 & 0.530 & 0.016 & 1.016 \\
\hline Post-Soviet Affairs & 0.873 & 0.276 & 0.481 & 0.065 & 0.952 \\
\hline Quantitative Marketing \& Economics & 1.292 & 0.414 & 0.608 & 0.087 & 1.255 \\
\hline Quarterly Journal of Economics & 1.137 & 0.100 & 0.513 & 0.024 & 1.087 \\
\hline Rand Journal of Economics & 1.459 & 0.424 & 0.646 & 0.045 & 1.417 \\
\hline Resource \& Energy Economics & 1.352 & 0.421 & 0.631 & 0.031 & 1.394 \\
\hline Review of Economic Studies & 1.250 & 0.200 & 0.575 & 0.028 & 1.331 \\
\hline Review of Economics \& Statistics & 1.107 & 0.251 & 0.534 & 0.011 & 1.022 \\
\hline Review of Environ. Economics \& Policy & 1.364 & 0.226 & 0.598 & 0.092 & 1.382 \\
\hline Review of Finance & 1.393 & 0.400 & 0.617 & 0.052 & 1.281 \\
\hline Review of Financial Studies & 1.022 & 0.159 & 0.497 & 0.008 & 0.965 \\
\hline Small Business Economics & 1.500 & 0.496 & 0.659 & 0.025 & 1.361 \\
\hline Socio-Economic Review & 1.398 & 0.347 & 0.612 & 0.053 & 1.272 \\
\hline Technological \& Economic Development of Economy & 1.699 & 0.353 & 0.680 & 0.039 & 1.539 \\
\hline Value in Health & 1.363 & 0.391 & 0.640 & 0.011 & 1.502 \\
\hline World Development & 1.196 & 0.362 & 0.580 & 0.008 & 1.165 \\
\hline
\end{tabular}

Notes: This tables reports the skewness coefficients from section reported in Figure 1. NC: Share of non-cited articles; Gini: Gini-Coefficient; $N H H$ : Normalized Herfindahl-Hirschman Index; $C V$ : Coefficient of Variation. 